\title{
Use of navigation GPSs in small topographical surveying - ERRATUM
}

Miguel Julio Machado Guimarães, Lucas Raimundo Da Silva Araújo, Cristina Akemi Mogami, Fábio Dos Anjos Rezende and Italo Emanuel Dos Anjos Santos

doi: $10.1017 /$ exp.2020.27, published online by Cambridge University Press: $9^{\text {th }}$ July

In the above mentioned paper (Guimarães et al., 2020) a typographical error was introduced into the title which has now been corrected. The publishers apologise for this error.

\section{Reference}

Guimarães, M., Da Silva Araújo, L., Mogami, C., Rezende, F., Santos, I., \& Shapiro, A. (2020). Use of navigation GPSs in small tospographical surveying. Experimental Results, 1, E19. https://doi.org/10.1017/exp.2020.27.

Cite this article: Guimarães MJM, Araújo LRDS, Mogami CA, Rezende FDA, Santos IEDA (2020). Use of navigation GPSs in small topographical surveying - ERRATUM Experimental Results, 1, e33, 1. https://doi.org/10.1017/exp.2020.40 